РЕГУЛИРУЕМЫЙ ЛИНЕЙНЫЙ

АСИНХРОННЫЙ ДВИГАТЕЛЬ С

КОРОТКОЗАМКНУТОЙ ОБМОТКОЙ ДЛЯ

МАГНИТНОЛЕВИТАЦИОННОГО

\title{
TРАНСПОРТА
}

\author{
В. А. Соломин, А. В. Соломин,
}

А. А. Бичилова, Л. Л. Замшина, Н. А. Трубицина

Ростовский государственный университет путей

сообщения

(Ростов-на-Дону, Россия)

\section{ADJUSTABLE LINEAR INDUCTION MOTOR WITH SHORT-CIRCUITED WINDING FOR MAGNETOGRAVITATIONAL TRANSPORT}

V. A. Solomin, A. V. Solomin, A. A. Bichilova, L. L. Zamchina, N. A. Trybitsina

Rostov State Transport University

(Rostov-on-Don, Russia)

В Ростовском государственном университете путей сообщения (РГУПС) разработан новый тип тяговой машины для магнитнолевитационного транспорта - линейный асинхронный двигатель, у которого обмотка вторичного элемента (ВЭ) выполнена короткозамкнутой с возможностью плавного изменения ее сопротивления. ЛАД с короткозамкнутой обмоткой ВЭ обладает такими же пусковыми и регулировочными возможностями, как и асинхронный двигатель с фазной обмоткой якоря. По мнению авторов, может оказаться эффективным сочетание частотного регулирования магнитнолевитационным транспортом с управлением путем 

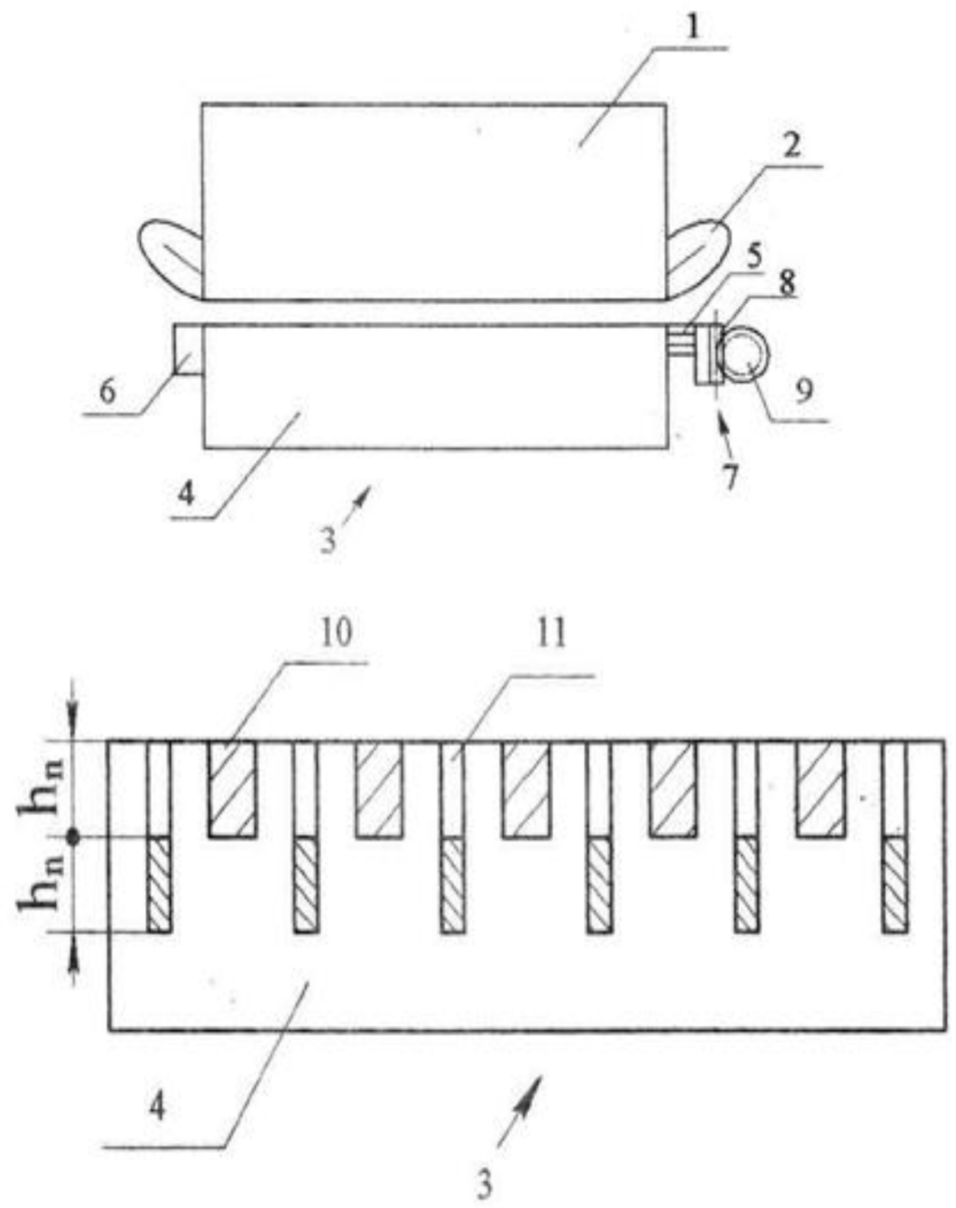

Рис. 1. Регулируемый ЛАД и его вторичный элемент изменения сопротивления короткозамкнутой обмотки ВЭ ЛАД соответственно при высоких и низких скоростях движения. 
Регулируемый линейный асинхронный двигатель с увеличенным пусковым усилием схематически показан на рис. 1 . Индуктор содержит 1 трехфазную обмотку 2, а в сердечнике 4 вторичного элемента 3 кроме основных пазов 10, в которых расположены стержни 5 основной короткозамкнутой обмотки ВЭ, выполнены дополнительные пазы 11 для размещения пусковой обмотки ЛАД. Стержни 12 пусковой короткозамкнутой обмотки размещены в нижних частях дополнительных пазов для увеличения эффекта вытеснения тока при пуске двигателя. Для увеличения пускового тягового усилия подвижный элемент замыкает только стержни пусковой обмотки. При «глубоком» расположении стержней 12 эффект вытеснения тока значителен, что позволит повысить пусковое тяговое усилие двигателя. По мере разгона ЛАД подвижный элемент замыкает частично одновременно стержни основной и пусковой обмоток ВЭ, а затем в номинальном режиме пусковая обмотка размыкается, а основная полностью закорачивается, что повышает КПД линейного двигателя.

\section{Сведения об авторах:}

СОЛОМИН Владимир Александрович, E-mail: ema@kaf.rgups.ru СОЛОМИН Андрей Владимирович, E-mail: vag@kaf.rgups.ru БИЧИЛОВА Анастасия Алановна, E-mail: ema@kaf.rgups.ru ЗАМШИНА Лариса Леонидовна, E-mail: ema@rgups.ru ТРУБИЦИНА Надежда Анатольевна, E-mail: ema@rgups.ru

\section{Information about the authors:}

Vladimir A. SOLOMIN, E-mail: ema@kaf.rgups.ru Andrey V. SOLOMIN, E-mail: vag@kaf.rgups.ru Anastasia A. BICHILOVA, E-mail: ema@kaf.rgups.ru Larisa L.ZAMSHINA, E-mail: ema@rgups.ru Nadezhda A. TRUBITSINA, E-mail: ema@rgups.ru 